Author version: Biogeosciences Discuss., vol.10; 2013; 16213-16236

\title{
Evolution of cyclonic eddies and biogenic fluxes in the northern Bay of Bengal
}

\author{
M. Nuncio ${ }^{1}$ and S. Prasanna Kumar ${ }^{2 *}$ \\ ${ }^{1}$ National Centre for Antarctic and Ocean Research, Head Land Sada, Vasco-da-Gama, Goa-403804, \\ India; Ph: 918322525530 \\ ${ }^{2}$ CSIR-National Institute of Oceanography, Dona Paula, Goa-403004, India; Ph: 918322450300 \\ ${ }^{*}$ Corresponding author - E-mail: Prasanna@nio.org
}

\begin{abstract}
The Bay of Bengal has been traditionally known for its low primary productivity and varied reasons were attributed to it. The data analysis from the sediment traps deployed in the northern Bay of Bengal during the 5 years from 1994 show episodic events of enhanced downward biogenic flux every year which was not related to monsoon-driven seasonal cycle. Satellite-derived sea level anomaly suggests that the episodic increase in the biogenic flux was associated with the presence of cyclonic eddies in the sediment trap location. Cyclonic eddy-induced down ward biogenic flux in the sediment trap location was larger than the amplitude, $\sim 40 \mathrm{mg} \mathrm{m}^{2} \mathrm{~d}^{-1}$, of the seasonal cycle. The magnitude of the peak episodic fluxes were one-and-half to two-and-half times the annual mean flux, while the anomaly of peak episodic fluxes was at least equal to or greater than the magnitude of the seasonal flux value. Cyclonic eddies responsible for high biogenic flux during 1994 and 1996 were formed in the northern Bay of Bengal during February - March of respective years due to the interaction of northward flowing western boundary current and coastally trapped Kelvin wave. In contrast cyclonic eddies during 1997 and 1998 were formed from the breaking of westward propagating Rossby waves. The sediment trap data provided the observational evidence that eddyinduced biological productivity is an important mechanism in the Bay of Bengal that contributes significantly to the mid-depth biogenic flux.
\end{abstract}

Key Words: Eddies, Bay of Bengal, coastally trapped Kelvin wave, Rossby waves, biogenic flux, chlorophyll, nutrients 


\section{Introduction}

The Bay of Bengal (BOB), located in the north-eastern part of the Indian Ocean, is considered to be a low productive basin. In the BOB precipitation exceeds the evaporation ( $2 \mathrm{~m} \mathrm{yr}^{-1}$ ) (Prasad, 1997). Three major river systems - the Ganges-Brahmaputra, Irrawaddy-Salween and the Krishna-Godavari - drain into the BOB. The total runoff from the peninsular rivers, which peaks during summer monsoon (June-September), amounts up to $2.95 \times 10^{12} \mathrm{~m}^{3} \mathrm{yr}^{-1}$ (Sengupta et al., 2006). This huge quantity of river runoff coupled with the excess precipitation induces large changes in the upper ocean salinity. The low salinity with high insolation (Narvekar and Prasanna Kumar, 2006) makes the BOB a highly stratified basin. Accordingly, the stability parameter in the BOB is 3-4 times greater than that in the Arabian Sea (AS), located in the north-western part of the Indian Ocean in the same latitudinal belt as that of the $\mathrm{BOB}$, making it increasingly difficult to perturb the upper water column in the BOB (Prasanna Kumar et al., 2002). The recently concluded Bay of Bengal Process Studies progmme (BOBPS), which conducted a large number of in situ biogeochemical measurements along the central and western BOB during 2001 to 2006, brought out two important results (1) the column integrated chlorophyll $a$ and primary productivity in the upper $120 \mathrm{~m}$ of the water column does not exhibit marked seasonal variability and (2) spring intermonsoon, which is generally ologotrophic in the northern Indian Ocean, was not the least productive season (Prasanna Kumar, et al., 2010). Note that based on limited data from the western BoB, Madhu et al. (2006) have suggested a similar lack of seasonality in the phytoplankton standing stock and production. A comparison of the surface as well as column integrated chlorophyll $a$ in the BOB with that of the AS during summer monsoon showed that it was $1 / 4^{\text {th }}$ and $1 / 8^{\text {th }}$ respectively of the AS values (Prasanna Kumaret al., 2002 \& 2004). This characteristic of low biological productivity in the BOB is attributed to several factors such as lack of prominent upwelling areas (La Fond, 1957; Murty and Varadachari, 1968; Shetye et al., 1991), strong stratification and absence of deep wind-mixing (Gomes et al, 2000; Prasanna Kuamar et al., 2002), cloud cover, sediment load (Qasim, 1977; Radhakrishna, 1978), and lack of winter-driven convective mixing (Jyothibabu et la., 2004; Prasanna Kumar et al., 2010).

In contrast to the above mentioned low surface and column integrated chlorophyll $a$ values in the $\mathrm{BOB}$, the sediment trap data revealed that the mid-depth organic particle (biogenic) flux in the BOB is comparable to that of the AS (Ramaswamy and Nair, 1994). This is intriguing since BOB lacks the traditional mechanisms of nutrient supply to the oligotrophic upper such as upwelling and winter convection that enhances the biological production. Explanation to this disconnect between the organic matter production in the euphotic zone and the sinking flux in the mid-depth in the BOB 
warrants alternate mechanism that couples bio-physical processes. One such mechanism is mesoscale eddies (Prasanna Kumar et al., 2004; Nuncio, 2007). Though eddies were reported in the BOB off Visakhapatnam way back in 1957 during March-April and October-November (Ramasastry and Balaramamrty, 1957) it took a while for the studies on eddies to catch-up . Advent of remote sensing added impetus to the studies on eddies. Legicks (1987) with the help of remote sensing delineated surface thermal characteristics of eddies during the late winter and spring intermonsoons. Later several studies reported the presence of eddies near the western boundary of the BOB (Babu et al., 1991; Murty et al., 1993; Shetye et al., 1993; Sanilkumar et al., 1997; Babu et al., 2003 ; Prasanna Kumar et al., 2004). It was Rao and Sastry (1981) who first examined the nutrient distribution along with physical properties in the vicinity of eddies in the BOB. However, studies that explored the role of meso-scale eddy in enhancing the biological productivity in the BOB is limited (Prasanna Kumar et al., 2004 \& 2007; Nuncio, 2007; Nuncio and Prasanna Kumar, 2012). It is in this context that we explore meso-scale eddies to understand the link between the production of organic matter in the upper ocean and its transportation into mid-depths in the BOB.

\section{Data and Methods}

The biogenic flux data used in this study was collected from November 1987 to November 1998 by using PARAFLUX Mark VI time-series sediment trap deployed at $17^{\circ} 27^{\prime} \mathrm{N}, 89^{\circ} 36^{\prime} \mathrm{E}$ (Fig.1) at nominal depth of $\sim 800-900 \mathrm{~m}$ in the northern Bay of Bengal (NBBT) (Unger et al., 2003). The sampling intervals of the sediment trap varied between 26 days to 42 days. From these values the monthly data for the entire time period was generated by linear interpolation. Though the biogenic flux data was available from 1987, in the present study we have utilized the data from 1994 to 1998 as satellite derived sea-level anomaly (SLA) was available only from 1994.

Evolution of eddies in relation to the biogenic flux was studied by analysing 7 day merged SLA of Topex-Posiedon/ERS/Jason satellites obtained from AVISO live access server for the period from 1994 to 1998 and has a spatial resolution of $1 / 3^{\text {rd }}$ of a degree (http://las.aviso.oceanobs.com). This is a proven tool in studying the meso-scale features of the ocean (Le Traon and Dibarboure, 1999) and the error associated SLA is about $3-6 \%$ of the variance of the signal.

In situ temperature and salinity data from World Ocean Atlas 2009 (Locarnini et al., 2009; Antonov et al., 2009) was used to compute velocity shear (U) to investigate the Rossby wave breaking. Velocity shear is computed using the thermal wind relationship

$$
\partial \mathrm{v} / \partial \mathrm{z}=-(\mathrm{g} / \mathrm{f})(\partial \rho / \partial \mathrm{x}), \partial \mathrm{u} / \partial \mathrm{z}=(\mathrm{g} / \mathrm{f})(\partial \rho / \partial \mathrm{y})
$$


where $\mathrm{u} / \mathrm{v}$ is the eastward/northward component of the geostrophic velocities, $\mathrm{g}$ is the acceleration due to gravity, $\mathrm{f}$ is the coriolis acceleration and $\rho$ is the density.

\section{Results and Discussion}

In this section we start with explaining the downward biogenic flux at the northern Bay of Bengal trap site (NBBT) (Fig.2) during 1994 to 1998, followed by the time evolution of sea level anomaly to identify the role of eddy in bringing about the changes in the biogenic flux. Finally, we examine the probable processes that lead to the generation of the cyclonic eddies that enhanced the biogenic flux.

\section{1 Biogenic flux and sea level anomaly}

The characteristic feature of the monthly mean climatology of the biogenic flux was (red line in Fig.2) the seasonal variability with a peak during summer monsoon (June-July) and the magnitude of the variability was $40 \mathrm{mg} \mathrm{m}^{-2} \mathrm{~d}^{-1}$ In contrast, the biogenic flux during individual years (black line in Fig.2) though showed five distinct peaks, two in 1994, and one each in 1996, 1997 and 1998, they did not always coincide with summer monsoon. In fact, the time of occurrence of the highest biogenic flux differed from year to year. In 1994, highest biogenic flux was observed during June followed by another peak in September, whereas during 1996 peak flux occurred during April. In 1997, September was characterised by the highest flux while in 1998 it was in July. An examination of the anomaly (green line in Fig.2), the difference between the biogenic flux and the monthly mean climatology, showed that it was always either comparable or larger than the magnitude of the seasonal variability. For example, during 1994 the peak anomalies were 40 and $50 \mathrm{mg} \mathrm{m}^{-2} \mathrm{~d}^{-1}$ respectively, while in 1996 it was $45 \mathrm{mg} \mathrm{m}^{-2} \mathrm{~d}^{-1}$. Similarly, in 1997and 1998 it was 95 and $40 \mathrm{mg} \mathrm{m}^{-}$ ${ }^{2} \mathrm{~d}^{-1}$ respectively. Also note that the peak biogenic fluxes during the above four years were one-andhalf to two-and-half times higher than the annual mean flux. Thus, both the biogenic flux as well as the anomaly in the above four years, suggests the role of physical forcing other than the seasonal variability in governing the export of biogenic flux. As cyclonic eddies have been suggested as one potential candidate capable of enhancing the biological (primary) productivity (see for e.g., Prasanna Kumar et al., 2004 \& 2007; Nuncio, 2007; Nuncio and Prasanna Kumar 2012), we examined the satellite derived sea-level anomalies (SLA) in the northern BOB during 1994 to 1998 to decipher their role in augment the biogenic flux.

Analysis of 7-day snapshot of SLA in the northern BOB during 1994 revealed the presence of a cyclonic eddy with negative SLA of about $25 \mathrm{~cm}$ during the second week of March near the northwestern boundary of the BOB $\left(18^{\circ} \mathrm{N}, 86^{\circ} \mathrm{E}\right)$ (Fig.3). We designate this cyclonic eddy as CE1-1994. In addition to the cyclonic eddy, the SLA also revealed the signature of northward flowing western 
boundary current and the coastally trapped Kelvin wave. This Kelvin wave is the upwelling Kelvin wave that propagates along the rim of the BOB during January-March (Rao et al., 2010; Srinivas et al., 2012). However, during this period the location of the sediment trap was approximately $350 \mathrm{~km}$ east ward of the eddy. We also noticed an elongated positive SLA oriented in the northwestsoutheast direction to the east of the cyclonic eddy extending over the location of NBBT. The CE11994 intensified during the third week of March and by the first week of April the eddy moved offshore and the positive SLA anomaly west of it began to dissipate. By the end of April 1994 the positive SLA anomaly was replaced by a negative anomaly and the shape of the cyclonic eddy became elliptical with its axis oriented in an east-west direction. During this time the biogenic flux showed gradual increase and reached a maximum value of $103.6 \mathrm{mg} \mathrm{m}^{-2} \mathrm{~d}^{-1}$ during June 1994 (Fig.2), while the eddy was undergoing an eastward translation. Another peak flux in 1994 occurred during September. At this time also a cyclonic eddy (CE2-1994) was seen in the vicinity of the sediment trap (Fig.4). However, unlike CE1-1994, the origin of CE2-1994 could not be traced back to the processes associated with the western boundary. This cyclonic eddy (CE2-1994) appears to have originated from the negative SLA near the trap location during August (see the panel for 3-Aug in Fig.4) which intensified and developed in to a cyclonic eddy (10-Aug panel in Fig.4). Note that CE2-1994 was located in the close proximity of NBBT during August and by September it started moving slowly north-westward, finally merging with CE1-1994. It was during this period that the biogenic flux showed another peak value of $91.6 \mathrm{mg} \mathrm{m}^{-2} \mathrm{~d}^{-1}$ (Fig.2).

The eddy (CE1-1996) responsible for the high biogenic flux during April 1996 was also formed during February in the northern BOB (Fig.5). At this time also the northward flowing western boundary current and the coastally trapped Kelvin wave was discernible. Once formed the eddy underwent a southward displacement approaching the trap location in April. Towards the end of April and beginning of May the eddy was on the trap location resulting in the observed enhancement of the biogenic flux of $115.5 \mathrm{mg} \mathrm{m}^{-2} \mathrm{~d}^{-1}$. Subsequently, the eddy translated towards east and dissipated.

Similarly, during 1997 we noticed the presence of cyclonic eddy coinciding temporally with the observed peak in biogenic flux. The 7-day snapshots of SLA showed negative anomaly (CE1-1997) along the north-eastern BOB as early as May (Fig.6). This is the time when the first upwelling Kelvin propagates along the rim of the BOB. This negative SLA intensified in to a cyclonic eddy (CE1-1997) towards the end of May and showed a south-westward movement during June. However, during this period the location of trap was characterised by an anticyclonic circulation resulting in lower than the normal downward flux (Fig.2). Towards the end of July the eddy CE1- 
1997 reached the trap location and was seen till the end of August, which resulted in the observed enhanced downward biogenic flux of $144.4 \mathrm{mg} \mathrm{m}^{-2} \mathrm{~d}^{-1}$.

In 1998 also the maximum downward biogenic flux was during July-August, which was associated with the presence of cyclonic eddy (CE1-1998) (Fig.8). The cyclonic eddy CE1-1998 and CE1-1997 had a similar evolutionary history. Initially, a north-south elongated negative SLA appeared close to the north-eastern BOB during March-April (Figure.7), which moved south-westward with time and subsequently developed into a cyclonic eddy (CE1-1998) in the vicinity of NBBT by May. The eddy stayed close to the trap location from May until first week of July leading to the observed increase in

the biogenic flux during this period with a peak value of $118.7 \mathrm{mg} \mathrm{m}^{-2} \mathrm{~d}^{-1}$ in July (Fig.2). The southward translation of CE1-1994 and CE1-1996 can be clearly seen from the time evolution of SLA from the hovmuller diagram (Figure.8, slanting thick black line). It is also evident from the figure that this southward translation of cyclonic eddy occurs in other years also (Fig.8, middle \& bottom panels).

Thus, the time period of peak biogenic flux at NBBT was characterised by the presence of cyclonic eddies in the vicinity of trap location. The magnitude of the peak fluxes were one-and-half to twoand-half times the annual mean flux, while the peak anomaly of flux was at least equal to or greater than the magnitude of the seasonal flux value. Two of the cyclonic eddy CE1-1994 and CE1-1996 were formed in the northern and north-western BOB respectively, while CE1-1997 and CE1-1998 was formed in the north-eastern BOB. Once formed, they translated to the trap location leading to the enhanced downward biogenic flux.

\section{2 Generating mechanism of meso-scale eddies}

The cyclonic eddies identified during the period from 1994 to 1998 could come from two distinct sources. One source is the northern and north-western boundary of the BOB and another one is the eastern boundary. In the northern boundary cyclonic eddies were formed during February when the northward flowing western boundary current is active and the first upwelling Kelvin wave reaches the northern boundary. A time-distance havmuller diagram of SLA along the coast from eastern to western Bay of Bengal 1994 and 1996 (Figure. 9) showed negative values during January to April indicating the presence of coastal Kelvin wave. The slope of this negative SLA had a distinct characteristic. Up to $2000 \mathrm{~km}$ the band of negative SLA was almost horizontal indicating a fast propagation of coastally trapped Kelvin wave. However, beyond $2000 \mathrm{~km}$ the band of negative SLA showed a slope steep slope, indicating a slower propagation. In addition, to the west of Kelvin wave propagation SLA was positive. Recall that in the 7-day snap shots a basin-wide SLA (Figure $3 \& 4$ ) a 
region of positive SLA was noticed, which was associated with the anticyclonic circulation in the western BOB. Hence, we infer that the slowing down of the Kelvin wave is a result of its interaction with the anticyclonic circulation. The obvious question is how could this result in the formation of CE1-1994 and CE1-1996?

Earlier studies have hypothesised the role of baroclinic instability associated with the interaction of northward and southward flowing coastal currents along the western boundary in the formation of eddies (Prasanna Kumar et al., 1992). Later, Nuncio (2007) and Nuncio and Prasanna Kumar (2012) suggested the interaction of westward propagating Rossbywaves and local wind stress curl as a reason for the baroclinic instability and subsequent meandering of the western boundary . Using a numerical model Kurien et al. (2010) concluded that baroclinic instability plays a key role in meander growth and eddy generation along the western boundary. The Kelvin wave encountered the northward flowing western boundary current in the northern BOB during February. Subsequent snapshots of SLA showed the formation of cyclonic eddy. Thus, the interaction of western boundary current and the Kelvin wave in the northern $\mathrm{BOB}$ should have triggered instabilities that resulted in formation of cyclonic eddies CE1-1994 and CE1-1996.

The generating mechanism of cyclonic eddies responsible for high biogenic flux during 1997 and 1998 was different. Satellite derived SLA showed westward propagation of negative SLA from the eastern boundary and most of the westward propagating disturbances in the sea surface height consists of non linear meso-scale eddies (Chelton et al., 2011). They further showed that the source region of eddies are eastern boundary of the ocean basins. In a recent study Chen et al (2012) identified nearly 10,000 eddies in the BOB during the time period 1993 to 2010 and showed that they undergo westward displacement. Srinivas, et al (2012) argued that Rossby waves are an important source of eddies in the Bay of Bengal. The time period of formation of CE1-1997 and CE1-1998 was characterised by the presence of upwelling Kelvin wave along the eastern boundary. It is well known that these Kelvin wave radiate upwelling Rossby waves in to the interior ocean. In a recent study, Isachsen et al. (2007) showed that Rossby wave breaks in to meso-scale eddies if the basin crossing time of Rossby waves is greater than the characteristic instability time given by $\mathrm{UL}_{\mathrm{b}} / \beta \mathrm{L}_{\mathrm{d}}{ }^{3}$, where $\mathrm{U}$ is the shear velocity, $\beta$ is the gradient of planetary vorticity and $\mathrm{L}_{\mathrm{b}}$ and $\mathrm{L}_{\mathrm{d}}$ represent the basin width and the Rossby deformation scale respectively. If this parameter is greater than one then Rossby wave breaks in to meso-scale eddies before they cross the basin. In the BOB $\mathrm{L}_{\mathrm{d}}, \mathrm{L}_{\mathrm{b}}$ can be taken as $10^{5}$ and $10^{6}$ respectively and $\beta$ to be $10^{11}$. This prescribes $U$ of the order of -1 below which the Rossby wave crosses the basin. The computation using thermal wind relationship show that in the BOB seldom $U$ is less than order -1 (Figure. 10), implying the tendency of Rossby 
wave to break. Hence, we infer that the CE1-1997 and CE1-1998 have resulted from the Rossby wave breaking.

\section{Summary and conclusion}

The time series data on the biogenic flux in the northern BOB showed events of enhanced downward flux each year during 1994 to 1998, which was characterised by the presence of cyclonic eddies in the vicinity of trap location. Of the four high downward flux events described in this study, two were associated with cyclonic eddies formed in the northern/north-western Bay of Bengal. Though CE11994 and CE1-1996 was formed during February-March of respective years high biogenic flux was noted only in summer monsoon in case of CE1-1994, whereas for CE1-1996 maximum biogenic flux was during spring intermonsoon. This is due to the temporal differences in the proximity of the eddy to the sediment trap location, which in turn is closely related to the translation speed of each eddy. Time-latitude plots of SLA in the northern Bay of Bengal showed that formation of these eddies and its subsequent southward translation occurs almost every year. These eddies are formed by the interaction of Kelvin wave propagating along the coastal boundary with the northward flowing western boundary current. The other two eddies CE1-1997and CE1-1998 were formed by the breaking of Rossby wave propagated from the eastern boundary. The present study reiterates the importance of meso-scale cyclonic eddies in the production and subsequent downward transfer of carbon to mesopelagic layer in the Bay of Bengal. However, presently it is not known whether this eddies would be biologically productive throughout their life span and how much would they contribute towards carbon sequestration of the basin.

\section{Acknowledgements}

Authors are thankful to P.M.Muraleedharan, late G.Nampoothiri and Jayu Narvekar for helping data collection. This work was supported by Ministry of earth sciences (MoES), New Delhi under the programme BOB Process studies (BOBPS). We acknowledge Director, NIO, Goa and Council of Scientific and Industrial Research (CSIR), New Delhi for all the support and encouragement. M. Nuncio acknowledges Director NCAOR for his keen interest and support. This is NIO contribution

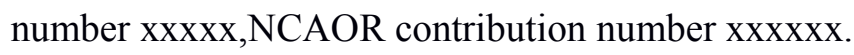




\section{References}

Antonov, J.I., Seidov, D., Locarnini, R.A., Mishonov, A.V., Boyer, T.P., Garcia, H.E., Baranova, O.K., Zweng, M.M. and Johnson, D.R.: World Ocean Atlas 2009, (1): Salinity, Edited by S. Levitus, NOAA Atlas, NESDIS 68, US Government printing Office, Washington, D.C., 184pp, 2009.

Babu, M.T., Prasanna Kumar, S. and Rao, D.P.: A subsurface cyclonic eddy in the Bay of Bengal, J. Mar. Res., 49, 403-410, 1991.

Babu, M.T., Sarma, Y.V.B., Murty, V.S.N. and Vethamony, P.: On the circulation in the Bay of Bengal during northern spring inter-monsoon (March-April 1987), Deep-Sea Res. II, 50, 855-865, 2003.

Chelton, D.B., Schlax, M. G. And Samelson, R.M.: Global observations of nonlinear mesoscale eddies, Prog. Oceanogr., 91,167-216, 2011.

Chen, G., Wang, D., Hou, Y.: The features and interannual variability mechanism of mesoscale eddies in the Bay of Bengal, Cont. Shelf. Res., 47, 178-185, 2012.

Gomes, H. R., Goes, J. I. and Saino, T.: Influence of physical processes and freshwater discharge on the seasonality of phytoplankton regime in the Bay of Bengal, Cont. Shelf Res., 20, 313-330, 2000.

Isachsen, P.E., La Casce, J.H. and Pedlosky, J.: Rossby wave instability and apparent phase speeds in large ocean Basins, J. Phys. Oceanogr.,37, 1177-1191, 2007.

Jyothibabu, R., Maheswaran , P.A., Madhu, N.V., Ashraf, T.T.M., Vijay, G.J., Haridas, P., Venugopal, P., Revichandran, C., Nair, K.K.C. and Gopalakrishnan, T.C.: Differential response of winter cooling on biological production in the northeastern Arabian Sea and northwestern Bay of Bengal, Curr. Sci., 87, 783-791, 2004.

Kurien, P., Ikeda, M. And Valsala, V.: Mesoscale variability along the east coast of India in Spring as revealed from satellite data and OGCM simulations, J. Oceanogr., 66, 273-289, 2010.

La Fond, E.C.: Oceanographic studies in the Bay of Bengal, Proc. Indian. Acad. Sci., 46B, 1-43, 1957.

Legeckis. R: Satellite observation of a western boundary current in the Bay of Bengal, J. Geophys. Res., 92, 12974-12978, 1987.

Le Traon P.Y. and Dibarboure, G.: Mesoscale mapping capabilities from multiple altimeter missions, J. Atmos. Ocean. Tech., 16, 1208-1223, 1999.

Locarnini, R.A., Mishonov, A.V., Antonov, J.I., Boyer, T.P., Garcia, H.E., Baranova, O.K., Zweng, M.M. and Johnson, D.R.: World Ocean Atlas 2009, (1): Temperature, edited by S. Levitus, NOAA Atlas, NESDIS 68, US Government printing Office, Washington, D.C., 184pp, 2009.

Madhu, N.V., Jyothibabu, R., Maheswaran, P.A., Vijay, G.J., Gopalakrishnan, T.C. and Nair, K.K.C.: Lack of seasonality in phytoplankton standing stock (chlorophyll $a$ ) and production in the western Bay of Bengal, Cont. Shelf Res., 26, 1868-1883, 2006.

Murty, V.S.N., Suryanarayana, A. and Rao,D.P.: Current structure and volume transport across $12^{\circ} \mathrm{N}$ in the Bay of Bengal, Indian J. Mar. Sci., 22, 12-16,1993. 
Murty, C.S. and Varadachari, V.V.R.: Upwelling along the east coast of India, Bull. Natl. Inst. Sci. India, 38, 80-86, 1968.

Narvekar, J. And Prasanna Kumar, S.: Seasonal variability of the mixed layer in the central Bay of Bengal and associated changes in nutrients and chlorophyll, Deep-Sea Res. I, 53, 820-835, 2006.

Nuncio, M.: Role of eddies in the Bay of Bengal circulation and hydrography and in the distribution of nutrients and chlorophyll, Ph.D thesis, Goa university, 2007.

Nuncio, M. and Prasanna Kumar, S.: Life cycle of eddies along the western boundary of the Bay of Bengal and their implications, J. Mar. Sys., 94, 9-17, 2012.

Prasad, T.G.: Annual and seasonal mean buoyancy fluxes for the tropical Indian Ocean, Curr. Sci., 73, 667-674, 1997.

Prasanna Kumar, S., Babu, M.T. and Rao, D.P.: Energy and generating mechanism of a subsurface, cold core eddy in the Bay of Bengal, Indian J. Mar. Sci., 21, 140-142, 1992.

Prasanna Kumar, S., Muraleedharan, P.M., Prasad, T.G., Gauns, M., Ramaiah, N., de. Souza, S.N., Sardesai, S. and Madhupratap, M. : Why is the Bay of Bengal less productive during summer monsoon compared to the Arabian Sea?, Geophys. Res. Lett., 29, doi:10.1029/2002GL016013,2002

Prasanna Kumar, S., Nuncio, M., Narvekar, J., Kumar, A., Sardesai, S., De Souza, S. N., Gauns, M., Ramaiah, N. and Madhupratap, M.: Are eddies nature's trigger to enhance biological productivity in the Bay of Bengal?, Geophys. Res. Lett., 31, L07309, doi:10..1029/2003G1019274, 2004

Prasanna Kumar, S., Nuncio, M., Ramaiah, N., Sardesai, S., Jayu Narvekar, Fernandes, V., Paul, J.T. : Eddy-mediated biological productivity in the BOB during fall and spring intermonsoons, Deep-Sea Res. I, 54, 1619-1640, 2007.

Prasanna Kumar, S., Nuncio, M., Narvekar, J., Ramaiah, N., Sardessai., S, Gauns, M., Fernandes, V., Paul, J.T., Jyothibabu, R. and Jayaraj, K.A.: Seasonal cycle of physical forcing and biological response in the Bay of Bengal, Indian. J. Mar. Sci., 39, 388-405, 2010.

Qasim, S. Z.: Biological productivity of the Indian Ocean, Indian J. Mar. Sci., 6, 122-137, 1977.

Radhakrishna, K.: Primary productivity of the Bay of Bengal during March-April 1975, Indian J. Mar. Sci., 7, 58-60, 1978.

Ramaswamy, V. and Nair, R.R. : Fluxes of material in the Arabian Sea and Bay of Bengal Sediment trap studies, . Proc. Indian Acad. Sci. Earth Planet. Sci., 103,189-210, 1994.

Ramasastry. A. A. and Balaramamurty, C.: Thermal fields and oceanic circulation along the east coast of India, Proc. Indian Acad. Sci. Earth Planet. Sci., 46, 293-323, 1957.

Rao, D.P. and Sastry, J.S.: Circulation and distribution of some hydrographical properties during the late winter in the Bay of Bengal, Mahasagar Bull. Nat. Inst. Oceanogr., 14, 1-16, 1981.

Rao, R.R., Girish Kumar, M.S., Ravichandran, M., Rao, A.R., Gopalakrishna, V.V. and Thadathil, P.: Interannual variability of Kelvin wave propagation in the wave guides of the equatorial Indian Ocean, the coastal Bay of Bengal and the southeastern Arabian Sea during 1993-2006, Deep-Sea Res. I, 57, 1-13, 2010. 
Sanilkumar, K.V., Kuruvilla,T.V., Jogendranath, D. and Rao, R.R. : Observation of the western boundary current of the Bay of Bengal, Deep-Sea Res. I, 44, 135-145, 1997.

Sengupta, D., Raj, B.G.N. and Shenoi, S.S.C.: Surface freshwater from Bay of Bengal runoff and Indonesian through flow in the tropical Indian Ocean, Geophys. Res. Lett., 33, doi:10.1029/2006GL027573, 2006.

Shetye, S.R., Shenoi, S.S.C., Gouveia, A.D., Michael, G.S., Sundar, D. and Nampoothiri, G.: Winddriven coastal upwelling along the western boundary of the BOB during the southwest monsoon, Cont. Shelf Res., 11, 1397-1408, 1991.

Shetye, S.R, Gouveia, A.D., Shenoi, S.S.C., Sundar, D., Michael, G.S. and Nampoothiri, G. : The western boundary current of the seasonal subtropical gyre in the Bay of Bengal, J. Geophys. Res., 98, 945-954, 1993.

Sreenivas, P., Gnanaseelan, C. and Prasad, K. V. S. R.: Influence of El Niño and Indian Ocean Dipole on sea level variability in the Bay of Bengal, Global and Planetary Change, 80,215-225, 2012. 


\section{Figure captions}

Figure.1. Location map showing the position $\left(17^{\circ} 27^{\prime} \mathrm{N}, 89^{\circ} 36^{\prime} \mathrm{E}\right)$ of northern Bay of Bengal sediment trap (NBBT; white cross inscribed within white circle) over laid with variance $\left(\mathrm{cm}^{2}\right)$ of mean sea-level anomaly during 1994-1998.

Figure.2. Downward biogenic flux $\left(\mathrm{mg} \mathrm{m}^{-2} \mathrm{~d}^{-1}\right)$ recorded at sediment trap in the Northern Bay of Bengal (NBBT). Black line is the total biogenic flux, red line indicates climatological monthly mean flux and green line represents the biogenic flux anomaly (difference from the climatological monthly mean). Filled rectangles on total flux indicate time period when trap data was interpolated linearly to fill for missing data points.

Figure.3 Evolution of the cyclonic eddy CE1-1994 during 1994 identified based on the 7-day snapshot of satellite derived SLA $(\mathrm{cm})$ obtained from AVISO. Small circle represents the NBBT location, while the big circle represents CE1-1994. Arrow along the western boundary indicates the direction of propagation of coastally trapped Kelvin waves and the large ellipse indicates the anticyclonic circulation near the western Bay of Bengal.

Figure.4 Evolution of the cyclonic eddy CE2-1994 during 1994 identified based on the 7-day snapshot of satellite derived SLA (cm) obtained from AVISO. Small circle represents the NBBT location, the big circle represents CE1-1994 and the dashed big circle represents CE2-1994.

Figure.5 Same as that for Figure.3 but during 1996 and the big circle represents CE1-1996.

Figure.6 Same as that for Figure.4 but during 1997 and the big circle represents CE1-1997.

Figure.7 Same as that for Figure. 4 but during 1998 and the big circle represents CE1-1998.

Figure.8. Latitude time diagram of SLA for the northern Bay of Bengal during 2005 to 2009. The solid black lines indicate the southward translation of eddies formed in the northern Bay of Bengal during late winter monsoon and spring intermonsoon.

Figure.9 Time distance diagram of SLA along the coastal boundary in the Bay of Bengal during 1994 (bottom left panel) and 1996 (top left panel). Large ellipse represents the anticyclonic circulation depicted in figures 3 and 5. The distance is taken from east to west along the coastal boundary as depicted in bottom right panel.

Figure.10 Climatological shear velocity in the northern Bay of Bengal $\left(18-22^{\circ} \mathrm{N} 93-84^{\circ} \mathrm{E}\right)$. A value of the order -1 indicate that Rossby wave is prone to instability in the Bay of Bengal. 


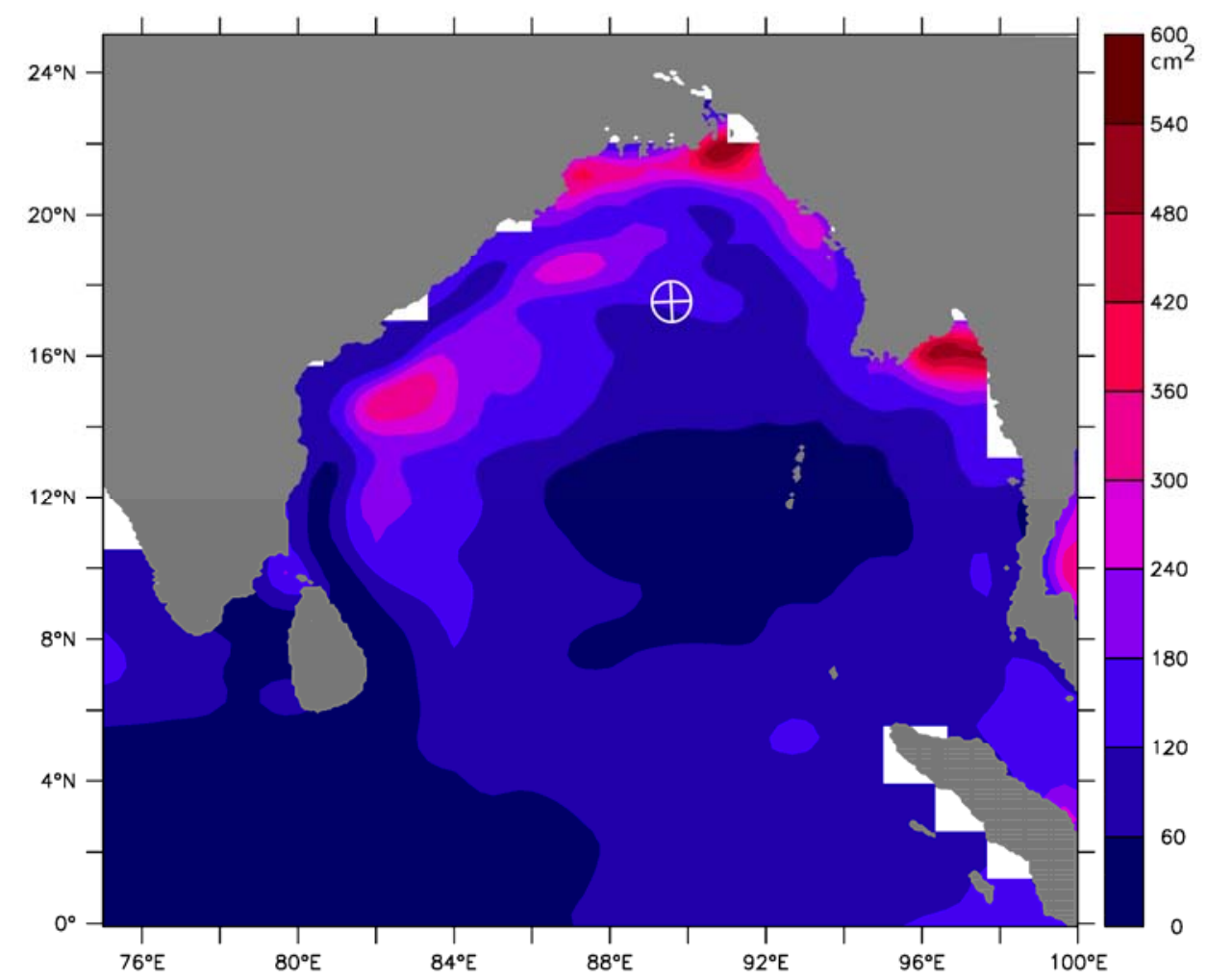

Figure.1

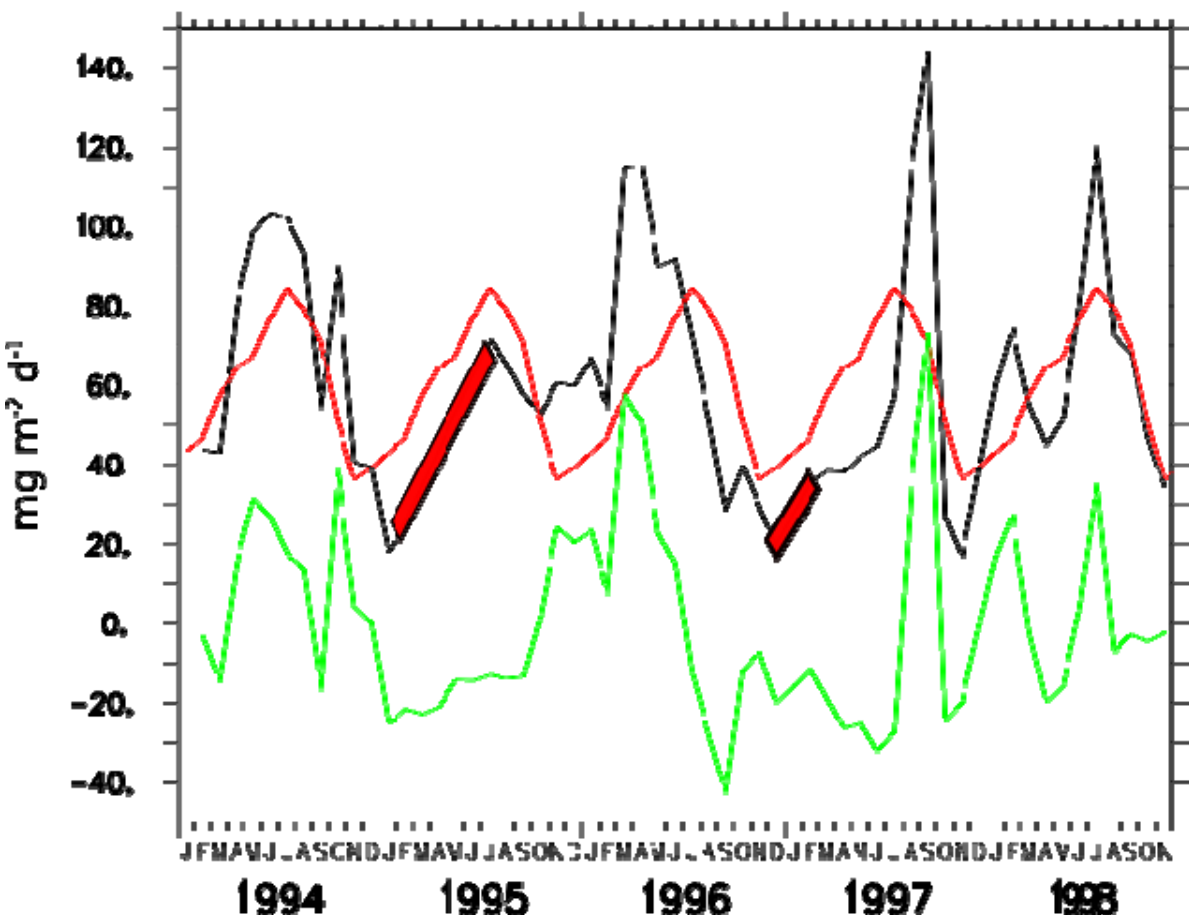

Figure.2 


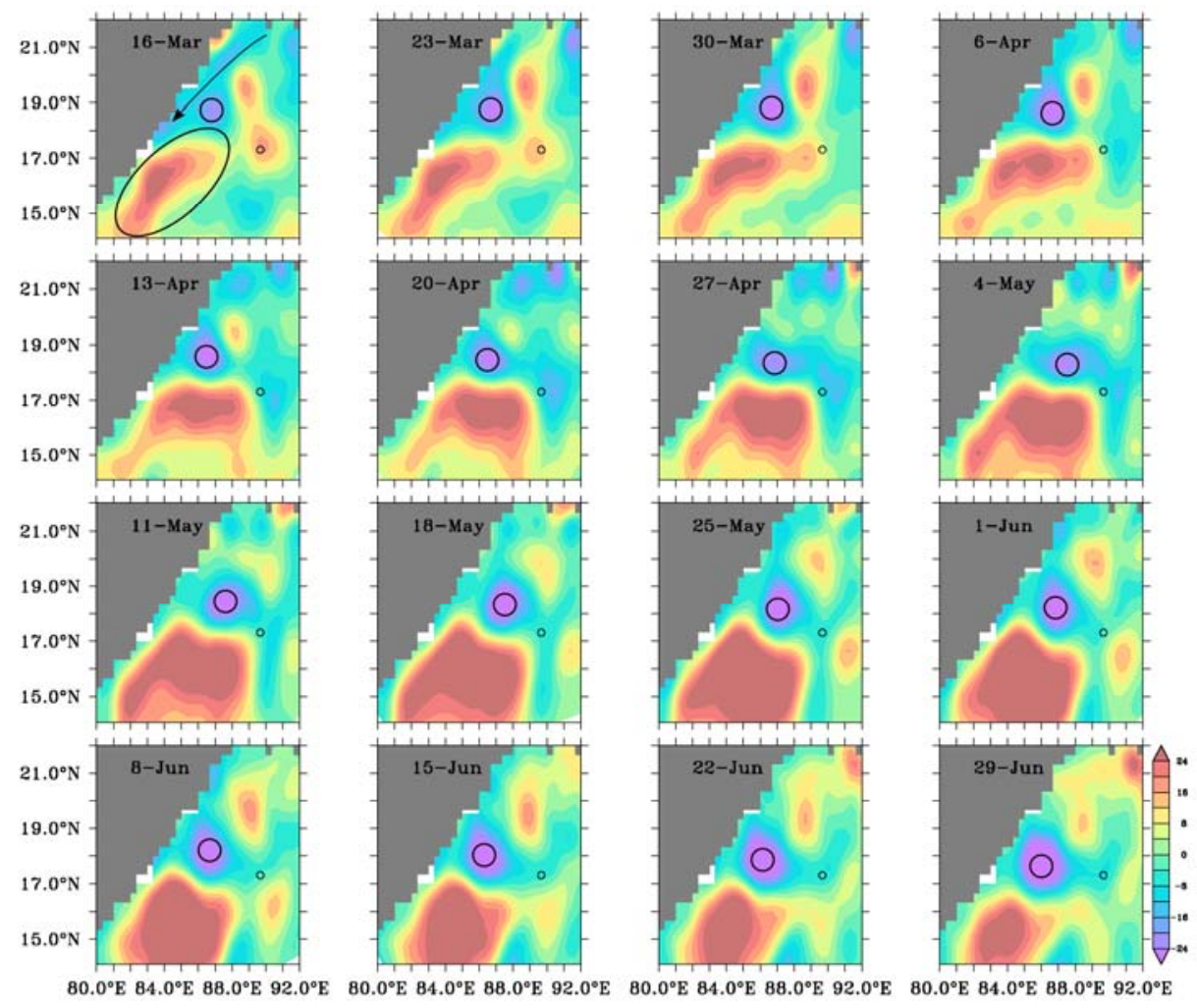

Figure.3
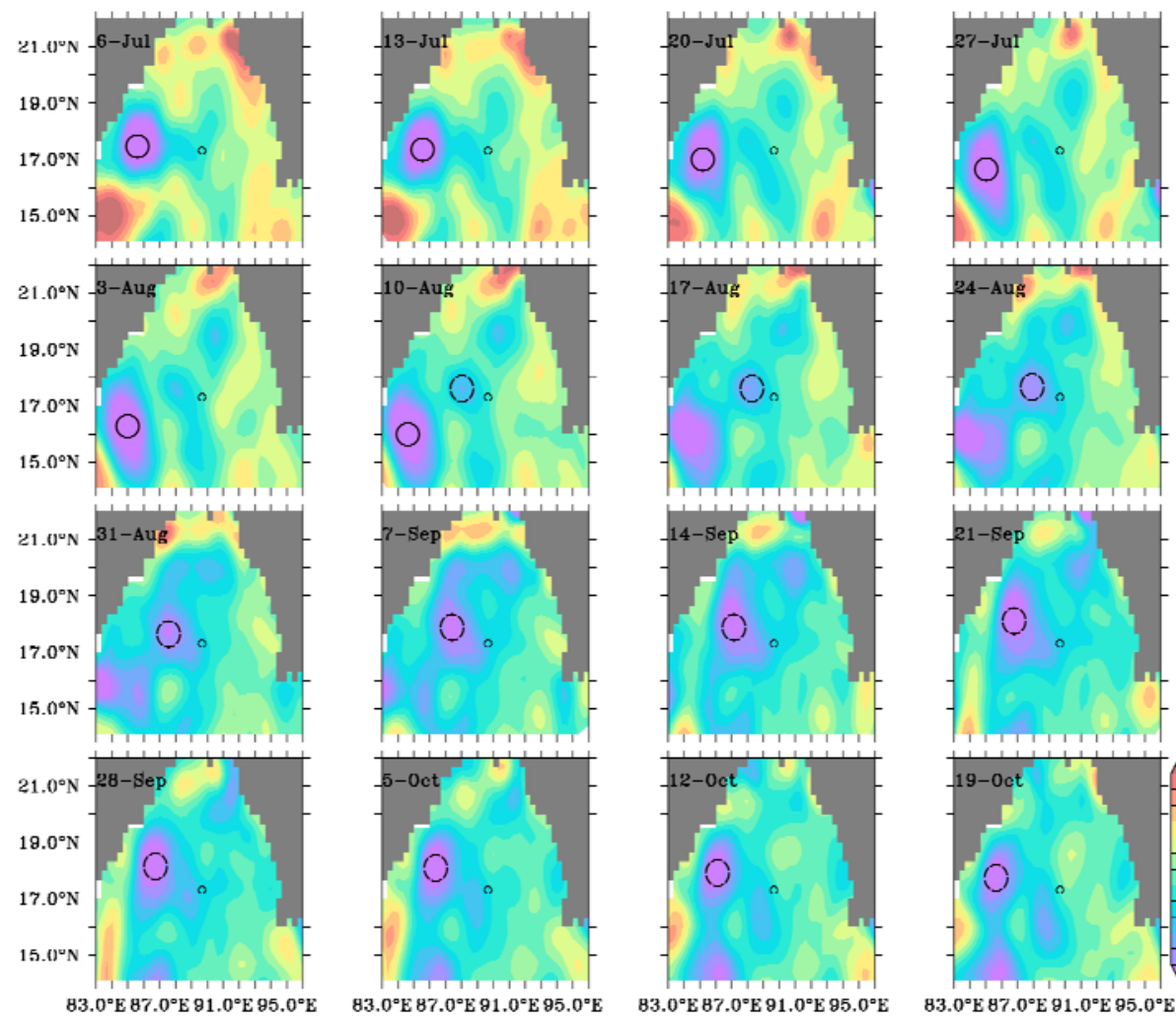

Figure.4 

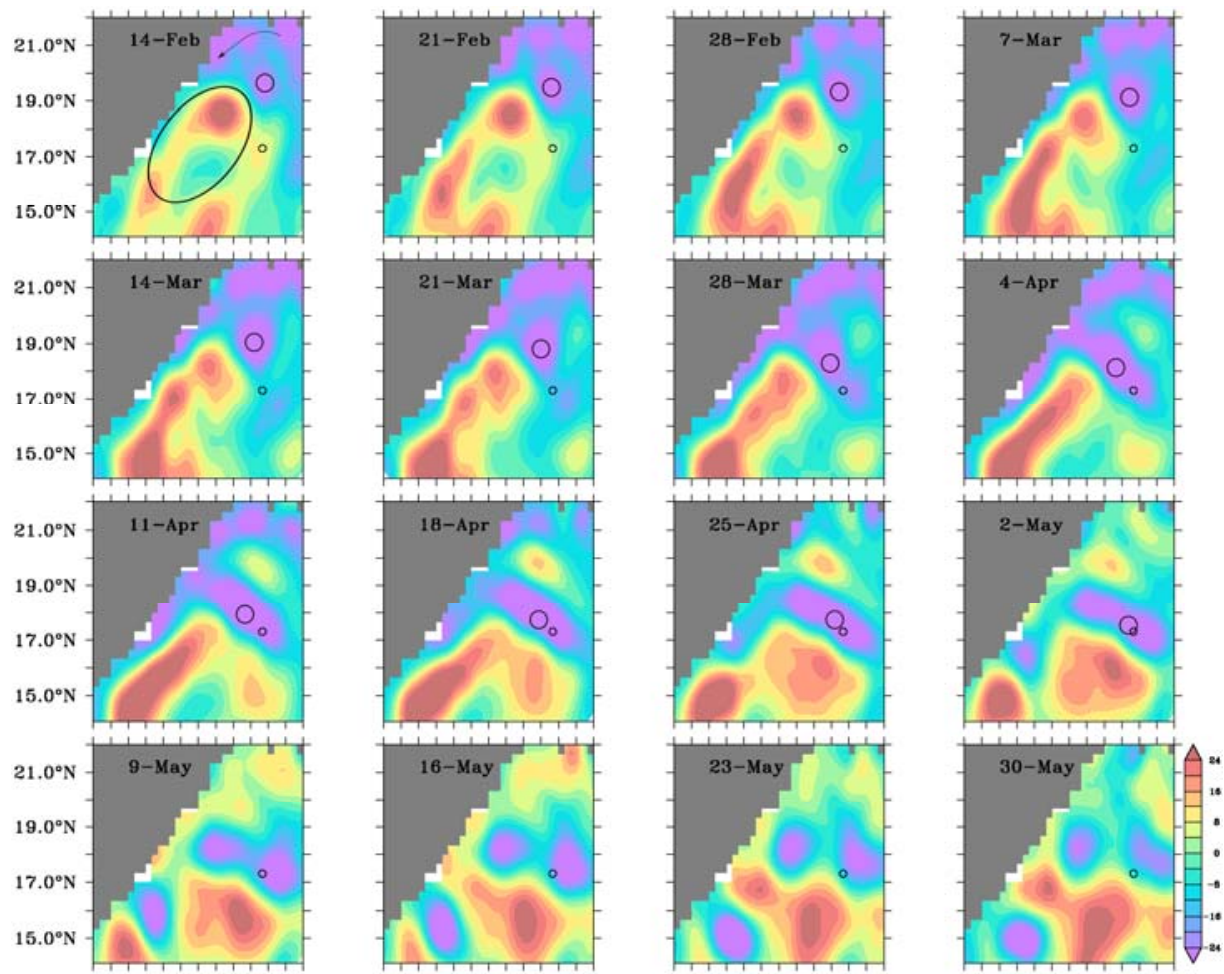

$80.0^{\circ} \mathrm{E} 84.0^{\circ} \mathrm{E} 88.0^{\circ} \mathrm{E} 92.0^{\circ} \mathrm{E} \quad 80.0^{\circ} \mathrm{E} \quad 84.0^{\circ} \mathrm{E} 88.0^{\circ} \mathrm{E} 92.0^{\circ} \mathrm{E} \quad 80.0^{\circ} \mathrm{E} 84.0^{\circ} \mathrm{E} \quad 88.0^{\circ} \mathrm{E} 92.0^{\circ} \mathrm{E} \quad 80.0^{\circ} \mathrm{E} 84.0^{\circ} \mathrm{E} 88.0^{\circ} \mathrm{E} 92.0^{\circ} \mathrm{E}$

\section{Figure.5}
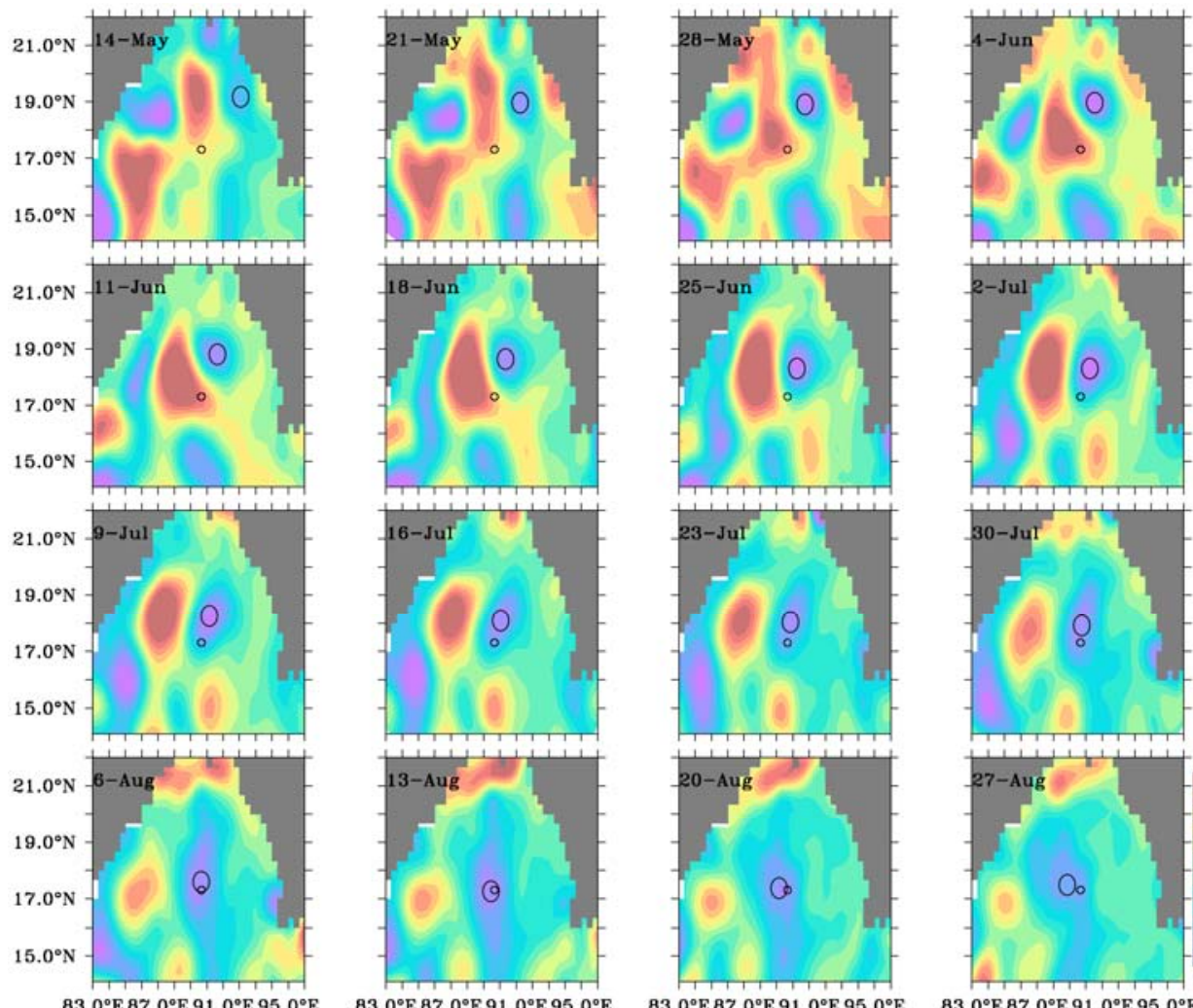

$83.0^{\circ} \mathrm{E} 87.0^{\circ} \mathrm{E} 91.0^{\circ} \mathrm{E} 95.0^{\circ}$

$83.0^{\circ} \mathrm{E} 87.0^{\circ} \mathrm{E} 91.0^{\circ} \mathrm{E} 95.0^{\circ} \mathrm{E}$

$83.0^{\circ} \mathrm{E} 87.0^{\circ} \mathrm{E} 91.0^{\circ} \mathrm{E} 95.0^{\circ} \mathrm{E}$

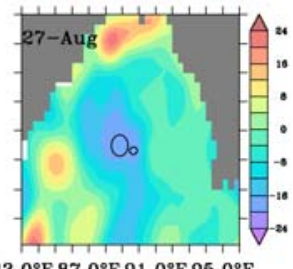

Figure.6 


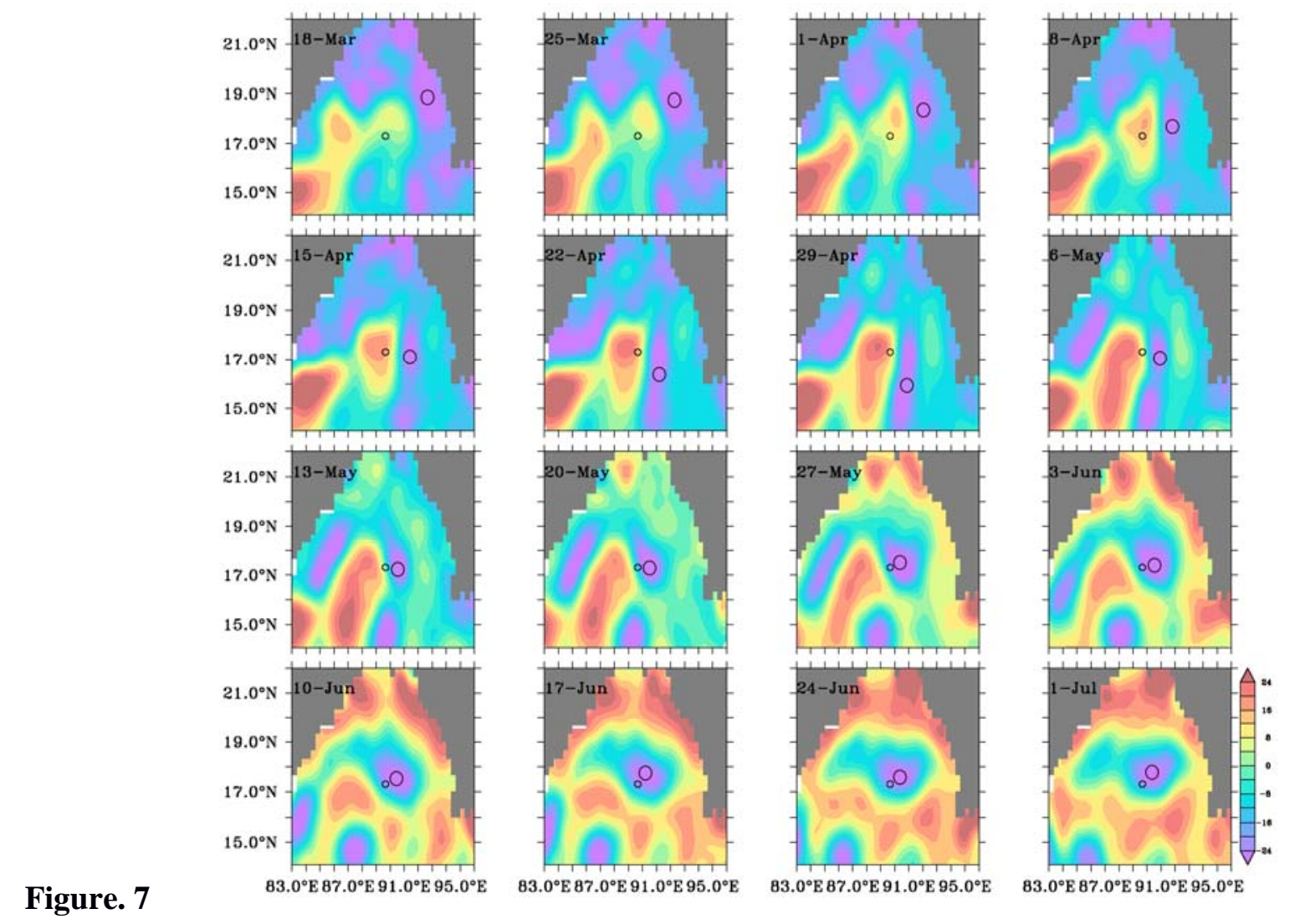

Figure. 7
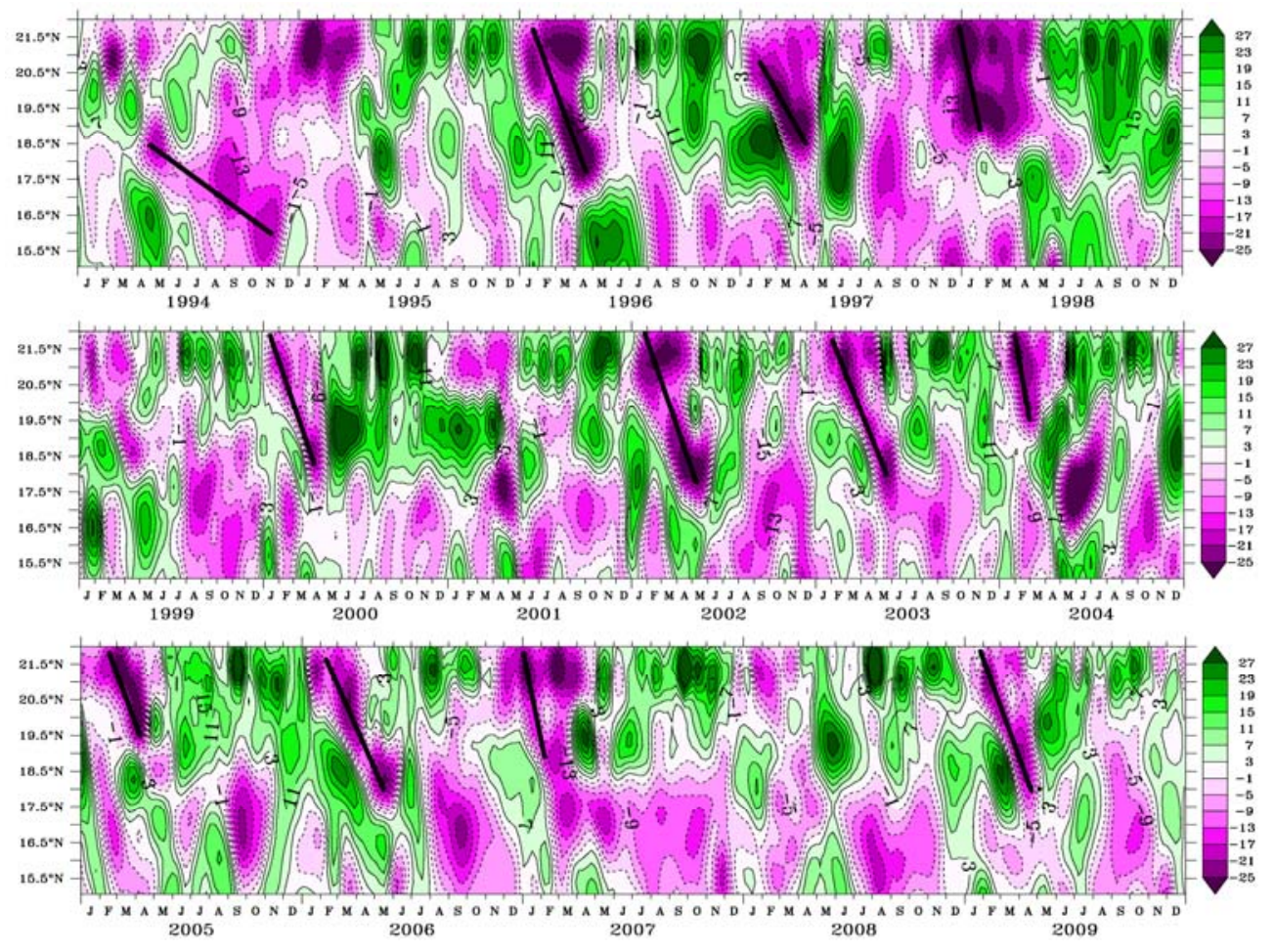

Figure.8 

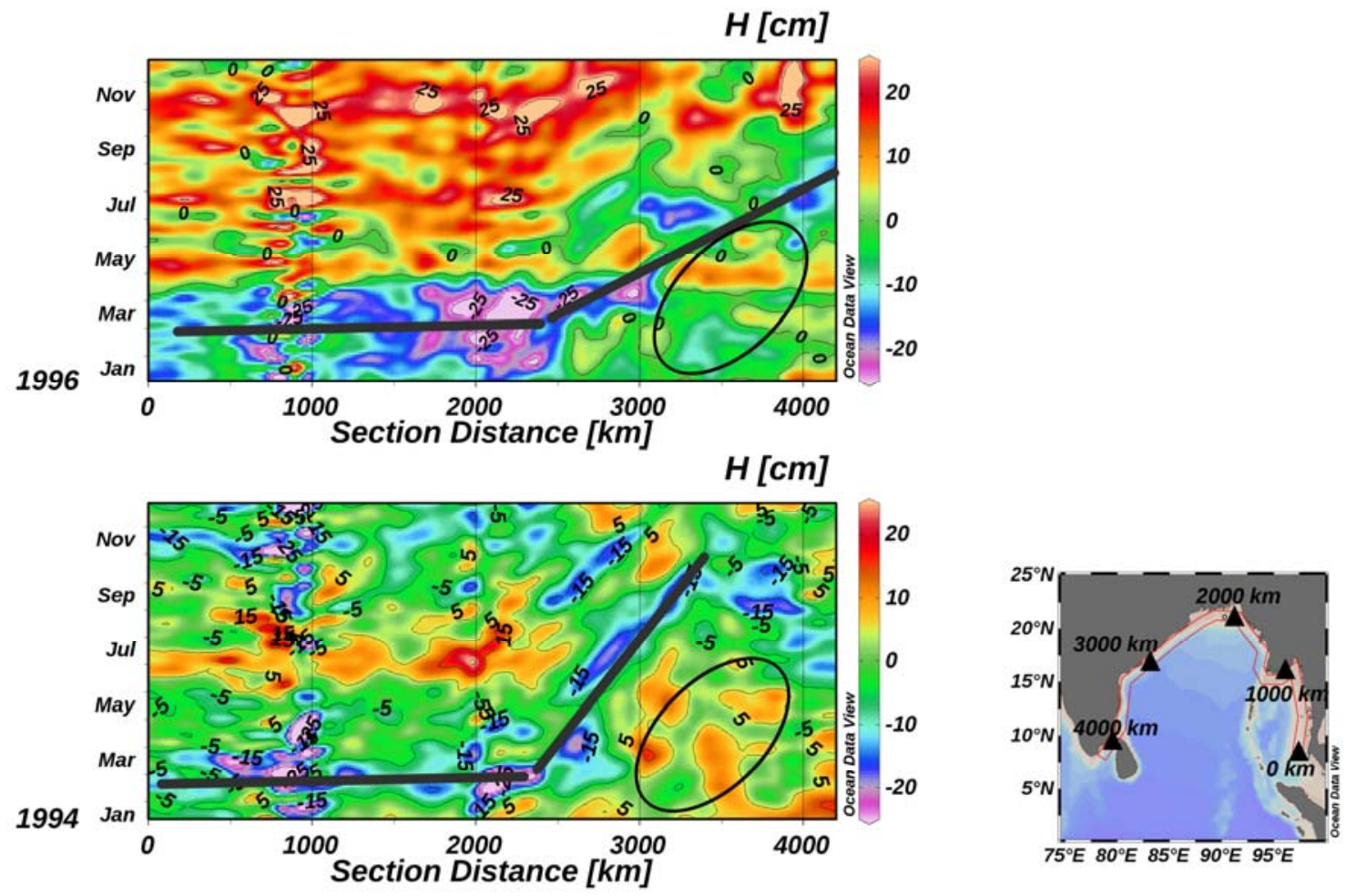

Figure.9

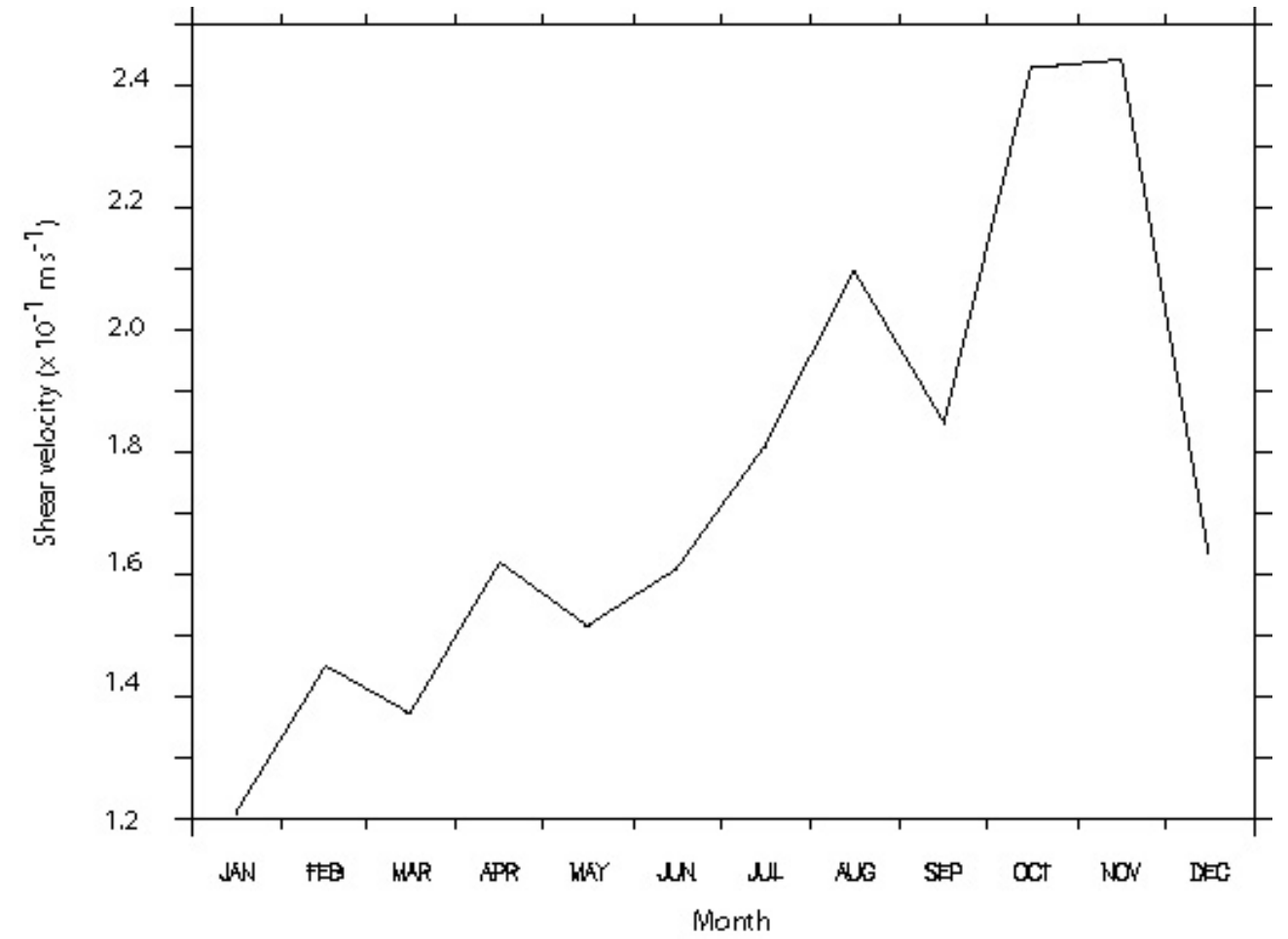

Figure.10 